Quim. Nova, Vol. 34, No. 2, 190-195, 2011

\title{
TRANSPORTE DE GLIFOSATO PELO ESCOAMENTO SUPERFICIAL E POR LIXIVIAÇÃO EM UM
} SOLO AGRÍCOLA

\author{
Gabriela Marina Pompeo Queiroz, Marcos Rivail da Silva e Renata Joaquim Ferraz Bianco \\ Departamento de Química, Universidade Regional de Blumenau, Rua Antônio da Veiga, 140, 89012-900 Blumenau - SC, Brasil \\ Adilson Pinheiro"e Vander Kaufmann \\ Departamento de Engenharia Civil, Universidade Regional de Blumenau, Rua São Paulo, 3250, 89030-000 Blumenau - SC, Brasil
}

Recebido em 17/11/09; aceito em 8/9/10; publicado na web em 8/12/10

\begin{abstract}
GLYPHOSATE TRANSPORT IN RUNOFF AND LEACHING WATERS IN AGRICULTURAL SOIL. Glyphosate was determined in runoff and leaching waters in agricultural soil that received an application of active ingredient and was exposed to simulated intensive rain conditions. The concentrations decreased during the simulation period and the concentrations of the runoff were higher than those achieved in the samples of leaching waters. The concentrations were lower than the pattern in the Brazilian Regulation MS N. 518/2004 for drinking water. The transported load of the applied active ingredient by the leaching was of $15.4 \%$ (w/w) and for the runoff was of $1.7 \%(\mathrm{w} / \mathrm{w})$.
\end{abstract}

Keywords: glyphosate; drainage; agricultural soil.

\section{INTRODUÇÃO}

Os herbicidas representam o grupo de praguicida mais empregado no mundo ${ }^{1}$ e têm sido usados extensivamente em práticas agrícolas para o controle de plantas infestantes. ${ }^{2}$ Dentre eles está o glifosato [n-(fosfonometil)glicina], $\mathrm{C}_{3} \mathrm{H}_{8} \mathrm{NO}_{5} \mathrm{P}$, que segundo dados de 2009 ${ }^{3}$ representa cerca de um terço do volume total de praguicidas comercializados no mercado brasileiro, estimando-se que no Brasil o consumo seja de 200 milhões de L por ano. O produto é usado em mais de uma centena de culturas, ${ }^{4}$ como soja, trigo, milho, algodão, feijão e arroz. $^{3}$

Embora o glifosato possua elevada eficiência na eliminação de ervas daninhas e seja citado como o mais vendido em todo o mundo, ${ }^{5}$ existem evidências de seus efeitos deletérios no ambiente como, por exemplo, destruição do habitat de animais inferiores e, em seres humanos, como edema pulmonar e dificuldade respiratória. ${ }^{6-8}$

Considerando os processos de transporte entre compartimentos ambientais, com os quais os herbicidas estão relacionados depois de aplicados em áreas agrícolas, a lixiviação e o escoamento superficial merecem destaque. ${ }^{9}$ Através da lixiviação, as moléculas de herbicidas podem ser conduzidas para camadas profundas do solo, podendo atingir e, assim, contaminar as massas subterrâneas de água. ${ }^{10} \mathrm{O}$ escoamento superficial favorece a contaminação das águas superficiais, que pode ocorrer através do transporte do herbicida adsorvido às partículas do solo erodido ou em solução. ${ }^{9}$

A adsorção do glifosato pode ocorrer devido à presença de matéria orgânica, óxidos de ferro e alumínio e, também, devido às argilas que compõem o solo. ${ }^{4}$ Uma vez adsorvido, o glifosato pode persistir durante anos no solo. ${ }^{11} \mathrm{O}$ glifosato apresenta elevada capacidade de adsorção, com coeficiente de partição entre o carbono orgânico do solo e a água de $21699 \mathrm{~mL} \mathrm{~g}^{-1}$, variando entre $884 \mathrm{~mL} \mathrm{~g}^{-1}$, em solo arenoso, e $60000 \mathrm{~mL} \mathrm{~g}^{-1}$, em solo argilo-siltoso. ${ }^{12}$

A mobilidade de um herbicida depende da capacidade de adsorção do solo. ${ }^{2}$ Solo com elevada capacidade de adsorção torna os herbicidas

*e-mail: pinheiro@furb.br pouco móveis e, como consequência, a permanência dos herbicidas no ambiente pode se tornar elevada. ${ }^{9}$ A permanência dos herbicidas também é influenciada pelos processos de degradação física, química ou biológica da substância.

A presença do herbicida glifosato tem sido detectada em águas superficiais 60 dias após a aplicação do produto,${ }^{13}$ indicando que essa substância é capaz de persistir no ambiente por determinado período de tempo. Tal fato chama a atenção para a necessidade de implementações de programas de monitoramento em ecossistemas aquáticos, em especial, os destinados ao abastecimento humano.

Várias formas de quantificação do glifosato têm sido utilizadas. Dentre elas, cromatografia em fase gasosa, ${ }^{14}$ cromatografia em fase líquida de alta eficiência, ${ }^{15}$ cromatografia de troca iônica, ${ }^{16}$ cromatografia em camada delgada, ${ }^{17}$ ressonância magnética nuclear de fósforo $31\left(\mathrm{RMN}^{31} \mathrm{P}\right),{ }^{18}$ espectrofotometria, ${ }^{19}$ polarografia ${ }^{20}$ e eletroforese. ${ }^{21}$

O objetivo deste trabalho foi estudar o transporte de glifosato pelo escoamento superficial e por lixiviação em um solo agrícola, submetido à simulação de chuva. Para isso, utilizou-se a técnica de cromatografia de troca iônica e estabeleceu-se um método contendo informações como limite de detecção e limite de quantificação.

\section{PARTE EXPERIMENTAL}

\section{Área de estudo}

O estudo de campo foi desenvolvido utilizando-se um lisímetro, instalado em outubro de 2007, em uma área agrícola na bacia do ribeirão Concórdia, no município de Lontras, Estado de Santa Catarina. Ele localiza-se na latitude $06^{\circ} 49^{\prime} 17,8^{\prime \prime}$, longitude $69^{\circ} 91^{\prime} 76,9^{\prime \prime}$ e altitude de $371 \mathrm{~m}$.

A área pertence à região do Alto Vale do Itajaí, onde o clima é subtropical e constantemente úmido. A temperatura média máxima varia entre 23,5 e $26^{\circ} \mathrm{C}$ e a precipitação anual entre 1320 e $1640 \mathrm{~mm} .{ }^{22}$ O uso e ocupação da bacia são constituídos por matas nativas, reflorestamentos, pastagens, plantações de milho, fumo, cebola e mandioca. O solo é classificado como Cambissolo Háplico Alumínico. ${ }^{23}$ Cerca 
de $50 \%$ do solo é composto por silte e $15 \%$ por argila. Na camada superficial do solo, de 0 a $25 \mathrm{~cm}$, o teor de matéria orgânica é de $2,4 \%(\mathrm{~m} / \mathrm{v})$ e a CTC é de $23,28 \mathrm{cmolc} \mathrm{L}^{-1} \cdot{ }^{24}$ No lisímetro é cultivado anualmente milho, em sistema de plantio convencional.

O lisímetro, ${ }^{25}$ de material acrílico de $8 \mathrm{~mm}$ de espessura e de $1 \mathrm{~m}^{2}$ de base, contém uma amostra de solo indeformada de $1 \mathrm{~m}^{3}$. A amostra é isolada lateralmente e no fundo, não permitindo trocas com o solo que lhe deu origem. Na parede de jusante do lisímetro, próximo da superfície do solo, existem 3 furos que, conectados através de flanges, coletam o escoamento superficial e, um furo próximo à base (1 $\mathrm{m}$ de profundidade) coleta o escoamento de lixiviação. ${ }^{26}$ Sobre ele, foi instalado um simulador de chuva, o qual permitiu o controle da intensidade da precipitação, com o auxílio de um pluviógrafo Davis ${ }^{\circledR}$ com logger registrador Novus ${ }^{\circledR}$, que registra dados de precipitação a cada $5 \mathrm{~min}$.

\section{Aplicação e amostragem}

O experimento foi realizado em julho de 2009 quando o solo do lisímetro se encontrava em pousio, com presença de resíduos vegetais. O solo foi revolvido em uma profundidade de $15 \mathrm{~cm}$. Imediatamente após o revolvimento foi aplicado Roundup Original ${ }^{\circledR}$, produto comercial que possui uma concentração de $36,0 \%(\mathrm{~m} / \mathrm{v})$ de ingrediente ativo de glifosato. Foi aplicado na dose de $2 \mathrm{~kg} \mathrm{ha}^{-1}$ do produto comercial. Ressalta-se que nos últimos anos o lisímetro não recebeu a aplicação de glifosato.

As simulações de chuva foram realizadas 24 e 48 h após a aplicação do glifosato. Na $1^{\mathrm{a}}$ simulação, a intensidade da chuva foi cerca de $136 \mathrm{~mm} \mathrm{~h}^{-1}$ e na $2^{\mathrm{a}}$ simulação, de $173 \mathrm{~mm} \mathrm{~h}^{-1}$. Estas chuvas correspondem a eventos pluviosos de intensidade elevada, cuja frequência de ocorrência é baixa. Cada simulação de chuva teve a duração de $60 \mathrm{~min}$. Intensidades diferentes foram empregadas visando verificar o efeito dessa variável sobre o transporte do glifosato em solo agrícola. Amostras de água superficial e lixiviada foram coletadas em intervalos de 5 min.

As amostras foram armazenadas em frascos de polietileno (300 $\mathrm{mL}$ ), acondicionadas em caixas de isolamento térmico e transportadas ao laboratório, onde foram imediatamente analisadas.

\section{Reagentes}

Foi empregado o padrão de glifosato de $99,7 \%$ de pureza, obtido da Sigma-Aldrich ${ }^{\circledR}$.

Foram usados $\mathrm{Na}_{2} \mathrm{CO}_{3}$ (grau analítico, Fisher Scientific), $\mathrm{NaHCO}_{3}$ (grau analítico, Fisher Scientific), $\mathrm{H}_{2} \mathrm{SO}_{4}$ (98\%, Fisher Scientific), $\left(\mathrm{CH}_{3}\right)_{3} \mathrm{SiCl}$ (98\%, Aldrich), $\mathrm{C}_{6} \mathrm{H}_{14}\left(99 \%\right.$, Vetec), e $\mathrm{CH}_{3} \mathrm{OH}(99,8 \%$, Vetec).

Todas as soluções, incluindo eluente, regenerante, soluçãoestoque e solução-padrão foram preparadas com água ultrapura (Direct-Q ${ }^{\circledR} 3 \mathrm{UV}$, Millipore), de resistividade $18,2 \mathrm{M} \Omega \mathrm{cm}\left(\mathrm{a} 25^{\circ} \mathrm{C}\right.$ ).

\section{Limpeza da vidraria}

Conforme adaptação dos procedimentos encontrados na literatura, ${ }^{27}$ para prevenir a alta adsorção de glifosato, as vidrarias foram silanizadas usando $5 \%$ de trimetildiclorossilano em n-hexano. Depois de 10 min de contato, elas foram enxaguadas duas vezes com n-hexano e depois com metanol.

\section{Análises de glifosato}

As amostras foram filtradas através de uma membrana (de acetato de celulose) de $0,45 \mu \mathrm{m}$ de porosidade e as concentrações de glifosato foram determinadas, em triplicata, por um cromatógrafo para troca iônica Dionex ${ }^{\circledR}$ ICS-90, equipado com um detector de condutividade (modelo DS5). Condições cromatográficas: coluna analítica IonPac ${ }^{\circledR}$ AS22 4 x $250 \mathrm{~mm}$, coluna de guarda IonPac ${ }^{\circledR}$ AG22 4 X 50 mm, supressora de micromembrana aniônica (AMMS ${ }^{\circledR} 3004 \mathrm{~mm}$ ), eluente 9,0 mmol L-1 $\mathrm{Na}_{2} \mathrm{CO}_{3} / 2,8 \mathrm{mmol} \mathrm{L}{ }^{-1} \mathrm{NaHCO}_{3}$ com vazão de $1,2 \mathrm{~mL}$ min $^{-1}$, regenerante $50 \mathrm{mmol} \mathrm{L}^{-1} \mathrm{H}_{2} \mathrm{SO}_{4}$ e loop de injeção de $250 \mu \mathrm{L}$.

\section{RESULTADOS E DISCUSSÃO}

\section{Curva analítica}

A curva analítica foi obtida através de soluções-padrão com concentrações de 0,$25 ; 0,50 ; 0,75 ; 1,00 ; 1,25$ e $1,50 \mathrm{mg} \mathrm{L}^{-1} \mathrm{de}$ glifosato. Na quantificação, considerou-se a área do pico ao invés da altura devido à assimetria do pico de glifosato. A curva analítica obtida proporcionou coeficiente angular de 0,4658 , coeficiente linear de $-0,004$, coeficiente de determinação $\left(r^{2}\right)$ de 0,9977 e coeficiente de correlação $(r)$ de 0,9988 .

A Figura 1 mostra um exemplo de cromatograma obtido para uma solução-padrão de glifosato, que apresentou um tempo de retenção de 16,09 min. Nesta figura, ainda, podem ser vistos os cromatogramas obtidos com uma amostra de água coletada no lisímetro e com uma amostra de água em branco (sem a presença do glifosato). O tempo de retenção diminuiu ligeiramente com o aumento da concentração de glifosato, fato que também foi relatado na literatura. ${ }^{28}$
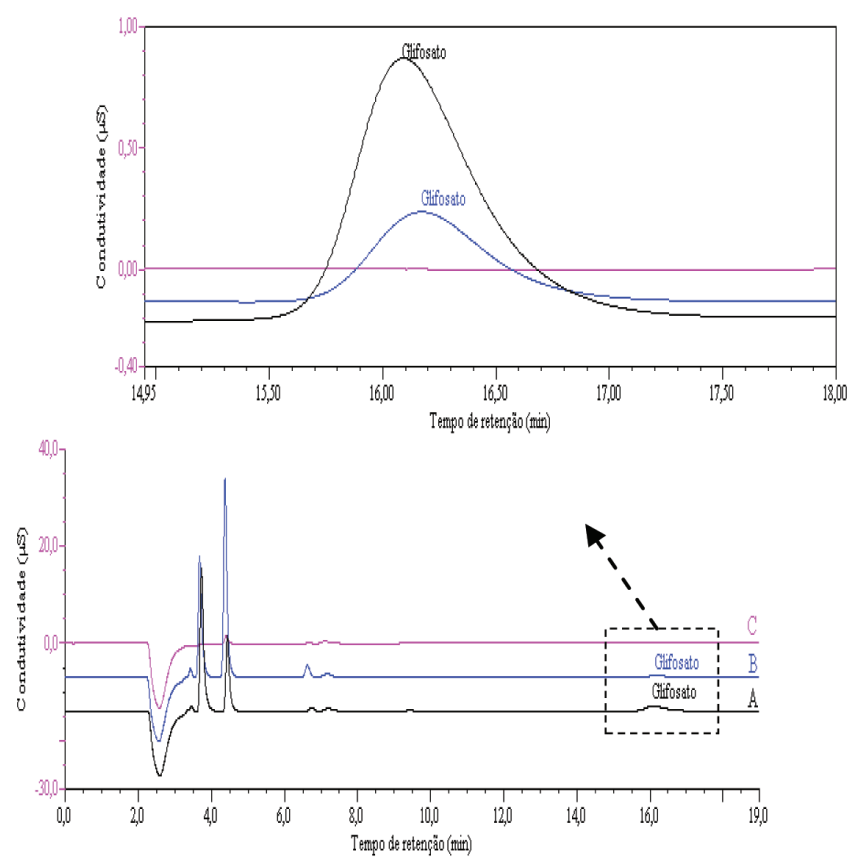

Figura 1. Cromatogramas obtidos: A) de uma solução-padrão de glifosato (1,50 $\left.\left.\mathrm{mg} \mathrm{L}^{-1}\right), B\right)$ de uma amostra de água coletada no lisímetro $\left(0,55 \mathrm{mg} \mathrm{L}^{-1}\right)$ $e$ C) de uma amostra de água em branco

Os limites de detecção (LD, $S / R=3$ ) e de quantificação (LQ, $S / R=10$ ) do método e do equipamento foram de 0,10 e $0,25 \mathrm{mg}$ $\mathrm{L}^{-1}$, respectivamente, uma vez que a amostra é submetida apenas ao processo de filtração.

\section{Interferência de ânions comuns}

Como a coluna analítica utilizada é aniônica, a interferência de ânions comuns na análise cromatográfica do glifosato foi avaliada 
Tabela 1. Concentrações de glifosato em amostras de água nos escoamentos superficiais e na lixiviação

\begin{tabular}{|c|c|c|c|c|}
\hline \multirow{3}{*}{$\begin{array}{l}\text { Tempo de simulação de } \\
\text { chuva (min) }\end{array}$} & \multicolumn{4}{|c|}{ Concentração de glifosato $\left(\mathrm{mg} \mathrm{L}^{-1}\right)^{*}$} \\
\hline & \multicolumn{2}{|c|}{24 h após a aplicação de glifosato } & \multicolumn{2}{|c|}{$48 \mathrm{~h}$ após a aplicação de glifosato } \\
\hline & Superficial & Lixiviação & Superficial & Lixiviação \\
\hline 15 & $0,630 \pm 0,001$ & $0,170 \pm 0,004$ & $0,150 \pm 0,002$ & ND \\
\hline 20 & $0,550 \pm 0,001$ & $0,170 \pm 0,001$ & $0,150 \pm 0,001$ & ND \\
\hline 25 & $0,350 \pm 0,002$ & $0,170 \pm 0,002$ & $0,130 \pm 0,002$ & ND \\
\hline 30 & $0,320 \pm 0,001$ & $0,160 \pm 0,002$ & $0,120 \pm 0,002$ & ND \\
\hline 35 & $0,290 \pm 0,004$ & $0,160 \pm 0,002$ & ND & ND \\
\hline 40 & $0,290 \pm 0,006$ & $0,160 \pm 0,002$ & ND & ND \\
\hline 45 & $0,260 \pm 0,006$ & $0,150 \pm 0,003$ & ND & ND \\
\hline 50 & $0,230 \pm 0,002$ & $0,150 \pm 0,002$ & $\mathrm{ND}$ & ND \\
\hline 55 & $0,200 \pm 0,002$ & $0,140 \pm 0,003$ & ND & ND \\
\hline 60 & $0,200 \pm 0,001$ & $0,140 \pm 0,001$ & ND & ND \\
\hline
\end{tabular}

*média das análises em triplicata $(\mathrm{n}=3) \pm$ desvio padrão. $\mathrm{ND}=$ não detectado.

comparando-se o tempo de retenção do glifosato com outros ânions: fluoreto $\left(\mathrm{F}^{-}\right)$, acetato $\left(\mathrm{CH}_{3} \mathrm{CO}_{2}^{-}\right)$, cloreto $\left(\mathrm{Cl}^{-}\right)$, nitrito $\left(\mathrm{NO}^{2-}\right)$, fosfato $\left(\mathrm{PO}_{4}^{3-}\right)$, nitrato $\left(\mathrm{NO}^{3-}\right)$ e sulfato $\left(\mathrm{SO}_{4}^{2-}\right)$. Verificou-se que esses ânions apresentaram tempos de retenção entre 3,30 e 6,15 min, demonstrando não interferirem na análise cromatográfica do glifosato.

\section{Determinação das concentrações nas amostras}

A Tabela 1 apresenta os resultados das determinações das concentrações de glifosato nas amostras de água, coletadas no lisímetro, no escoamento superficial e na lixiviação. As concentrações de glifosato no escoamento superficial foram superiores àquelas da lixiviação. A máxima concentração foi obtida na primeira amostra, 15 min após o início da simulação de chuva. No escoamento superficial a concentração máxima foi de $0,63 \mathrm{mg} \mathrm{L}^{-1}$ e na lixiviação, inferior a $0,17 \mathrm{mg} \mathrm{L}^{-1}$. Ressalta-se que as concentrações inferiores a $0,25 \mathrm{mg}$ $\mathrm{L}^{-1}$ são valores aproximados, em decorrência de serem inferiores aos limites de quantificação.

Nota-se que a concentração de glifosato na lixiviação, 24 h após a aplicação, foi resultante de seu movimento com a água percolada no perfil do solo, no intervalo de tempo anterior à simulação de chuva. Este movimento pode ser influenciado pela alta solubilidade que o glifosato possui em água $\left(12 \mathrm{~g} \mathrm{~L}^{-1}\right.$ a $\left.25^{\circ} \mathrm{C}\right) .{ }^{11}$

Tem sido relatado que o glifosato apresenta alta mobilidade vertical em solo tratado e rapidamente pode atingir altas concentrações nos horizontes mais profundos, onde a degradação é lenta. No estudo foi encontrado glifosato na solução de um solo, pouco tempo após a sua aplicação, a $30 \mathrm{~cm}$ de profundidade. ${ }^{29}$

A Tabela 1 mostra ainda que as concentrações do herbicida foram decrescentes ao longo do tempo de simulação da chuva. No entanto, o decréscimo foi mais importante no escoamento superficial do que na lixiviação. $\mathrm{Na} 1^{\mathrm{a}}$ simulação, a concentração de glifosato no último intervalo de tempo foi de $0,20 \mathrm{mg} \mathrm{L}^{-1}$ no escoamento superficial e de $0,14 \mathrm{mg} \mathrm{L}^{-1}$ na lixiviação. Assim, o decréscimo na água superficial foi da ordem de $70 \%$, enquanto que na lixiviação foi da ordem de $20 \%$. Este comportamento na evolução das concentrações pode ser explicado pelo fato de que a lixiviação é alimentada pela quantidade de glifosato transportada no perfil do solo ao longo da simulação. Na superfície do solo, a quantidade disponível de glifosato é reduzida à medida que a substância é transportada pela água de lixiviação no perfil do solo, pelo escoamento superficial e pela degradação biótica e abiótica.
$\mathrm{Na} 2^{\mathrm{a}}$ simulação, realizada 48 h após a aplicação do herbicida, somente foram detectadas concentrações no escoamento superficial. Elas foram detectadas até o final da primeira meia hora de simulação. A concentração obtida no início da $2^{a}$ simulação foi da mesma ordem de grandeza daquela determinada no final da $1^{a}$ simulação. Isto indica que a quantidade de glifosato disponível na camada superficial do solo pode não ter sido muito reduzida no intervalo de tempo entre as duas simulações. Isso pode ter sido devido à aplicação de uma elevada quantidade de água pelo simulador, que resultou em uma umidade próxima ao estado de saturação do solo, o que pode levar a reduzir a atividade microbiana na camada superficial do solo.

$\mathrm{Na}$ literatura, existem alguns relatos de estudos envolvendo a determinação de glifosato em amostras de águas superficiais. As concentrações encontradas são bem variadas. Em um estudo, realizado em áreas de cultivo de soja na Argentina, foram relatados resultados de concentrações de glifosato entre 0,1 e $0,7 \mathrm{mg} \mathrm{L}^{-1} .^{30}$

Outro trabalho envolvendo 51 cursos de água, em 9 estados do meio-oeste americano durante as diferentes fases agrícolas, determinou concentrações do herbicida maiores ou iguais a $0,1 \mu \mathrm{g} \mathrm{L} \mathrm{L}^{-1} \mathrm{em}$ $35 \%$ das amostras coletadas em pré-emergência, em $40 \%$ de amostras pós-emergência e em $31 \%$ de amostras na fase de colheita, com uma concentração máxima de $8,7 \mu \mathrm{g} \mathrm{L^{-1 }}$. Assim, a concentração do glifosato foi bastante inferior ao padrão de contaminação de $700 \mu \mathrm{g}$ $\mathrm{L}^{-1}$ estabelecido pela Agência de Proteção Ambiental (U.S. EPA). ${ }^{31}$

No estado do Rio Grande do Sul, foi detectada a presença de glifosato em 46,7\% das amostras de água analisadas de um rio. A maioria das amostras apresentou concentrações da ordem de 20 a $30 \mu \mathrm{g} \mathrm{L}^{-1}$. $^{13}$

Em outro estudo, no estado de São Paulo, avaliou-se as concentrações de glifosato nas águas superficiais da bacia do Rio Corumbataí, cuja atividade agrícola principal é o cultivo de cana-de-açúcar. Nele o glifosato não foi detectado em níveis quantificáveis, ocorrendo em concentrações inferiores a $1 \mu \mathrm{g} \mathrm{L} \mathrm{L}^{-1}$.32

A Resolução do CONAMA n ${ }^{\circ} 357 / 2005$, que dispõe sobre a classificação dos corpos de água, estabelece como valor máximo permitido para águas de classe II a concentração de glifosato de 0,065 $\mathrm{mg} \mathrm{L}^{-1} \cdot{ }^{33}$ A Portaria brasileira no 518/2004 do Ministério da Saúde estabelece como padrão de potabilidade das águas para consumo humano a concentração máxima de glifosato de $0,5 \mathrm{mg} \mathrm{L}^{-1} \cdot{ }^{34}$ Neste sentido, observa-se que apenas as duas primeiras amostras apresentaram concentrações superiores ao padrão de potabilidade.

Dois pontos devem ser ressaltados em relação às concentrações obtidas com a simulação de chuvas no lisímetro. Primeiro, elas repre- 
sentam contribuições de áreas que foram submetidas às aplicações do herbicida e que, imediatamente após a aplicação, tenha ocorrido uma precipitação, provocando o movimento no perfil do solo e, lateralmente, na superfície. O segundo ponto está relacionado à intensidade da precipitação. A intensidade simulada foi bastante superior àquelas que correntemente são observadas na região. ${ }^{35}$

Esta condição exprime que as concentrações poderiam ser maiores do que normalmente podem ser observadas em áreas agrícolas submetidas às chuvas com padrão médio regional.

Além disso, é importante ressaltar que o transporte do glifosato é influenciado pela composição do solo, principalmente pelo teor de matéria orgânica e argila. A camada superficial do solo apresenta baixo teor de argila, mas matéria orgânica elevada. A capacidade de adsorção do solo com essas características é elevada. A mobilidade do glifosato pode ter sido devida a macroporos do solo, que facilitam o movimento de substância com elevada capacidade de adsorção.

\section{Cargas de glifosato}

A carga indica a quantidade de glifosato transportado pelo escoamento superficial e/ou pela lixiviação. Esta quantidade é exportada da área de aplicação ao ambiente exterior, como corpos de águas superficiais e águas subterrâneas. A carga é obtida pelo produto entre a concentração, a vazão escoada e o intervalo de tempo de amostragem. Ela pode ser relacionada com a quantidade total aplicada, indicando o percentual que atinge os ambientes externos.

A Figura 2 apresenta as evoluções temporais das vazões escoadas na camada superficial e no fundo do lisímetro. Nota-se que as vazões escoadas no fundo são maiores do que na superfície. No $1^{\circ}$ dia de simulação, a diferença entre as vazões superficiais e de lixiviação foram maiores do que no $2^{\circ}$ dia. No $1^{\circ}$ dia, esta diferença foi da ordem de 30 vezes, enquanto que no $2^{\circ}$ dia, a diferença baixou para cerca de 5 vezes. Isto pode ter ocorrido devido ao aumento da umidade superficial do solo na $2^{\mathrm{a}}$ simulação, gerando maior escoamento superficial. Além disso, o transporte de material fino no $1^{\circ}$ dia, devido ao revolvimento do solo, realizado no momento em que foi feita a aplicação de glifosato, pode ter reduzido a condutividade hidráulica no perfil do solo, reduzindo assim o escoamento de lixiviação. A conduvidade hidráulica é afetada pela alteração de macroporos do solo, os quais podem favorecer o transporte por fluxo preferencial.

A Figura 3 mostra as cargas de glifosato transportadas em cada intervalo de amostragem de água, no escoamento superficial e na lixiviação. A quantidade de glifosato transportada pela lixiviação no $1^{\circ}$ dia de simulação foi mais elevada do que aquela transportada pelo escoamento superficial. A carga máxima na lixiviação foi de $1,33 \mathrm{mg}$ no intervalo de $5 \mathrm{~min}$. No escoamento superficial, a carga máxima foi da ordem de $0,075 \mathrm{mg}$, no mesmo intervalo de tempo. No $2^{\circ}$ dia, a lixiviação apresenta carga nula, pois não foram detectadas concentrações nas águas amostradas nesta camada do solo. É possível que alguma quantidade de glifosato tenha sido transportada, mas devido ao limite de detecção do processo analítico ela não pode ser detectada. No escoamento superficial, as quantidades transportadas nos primeiros intervalos de tempos apresentaram-se superiores àquelas do dia anterior. A carga máxima transportada no $2^{\circ}$ dia foi de $0,18 \mathrm{mg}$.

A Figura 4 apresenta as cargas de glifosato acumuladas ao longo do tempo nas amostras de água coletadas no lisímetro, no escoamento superficial e na lixiviação. Nota-se que a carga acumulada de glifosato transportada pela lixiviação seguiu uma tendência quase linear no $1^{\circ}$ dia e constante no $2^{\circ}$ dia. No caso do escoamento superficial, a evolução temporal foi um pouco diferente.

Verifica-se que o transporte total de glifosato pela lixiviação foi de $11,06 \mathrm{mg}$ e no superficial, de $1,25 \mathrm{mg}$. No $1^{\circ}$ dia de simulação, o
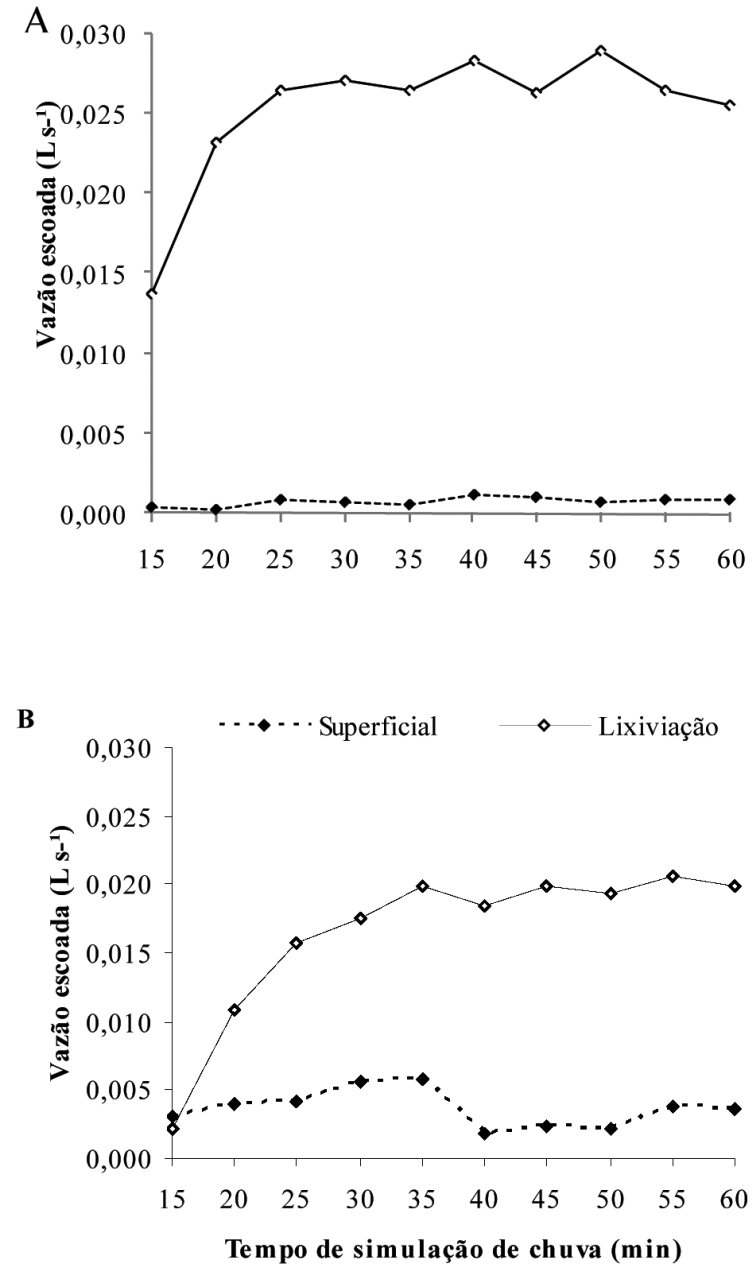

Figura 2. Evoluções temporais das vazões escoadas após A) 24 h e B) 48 h da aplicação de glifosato

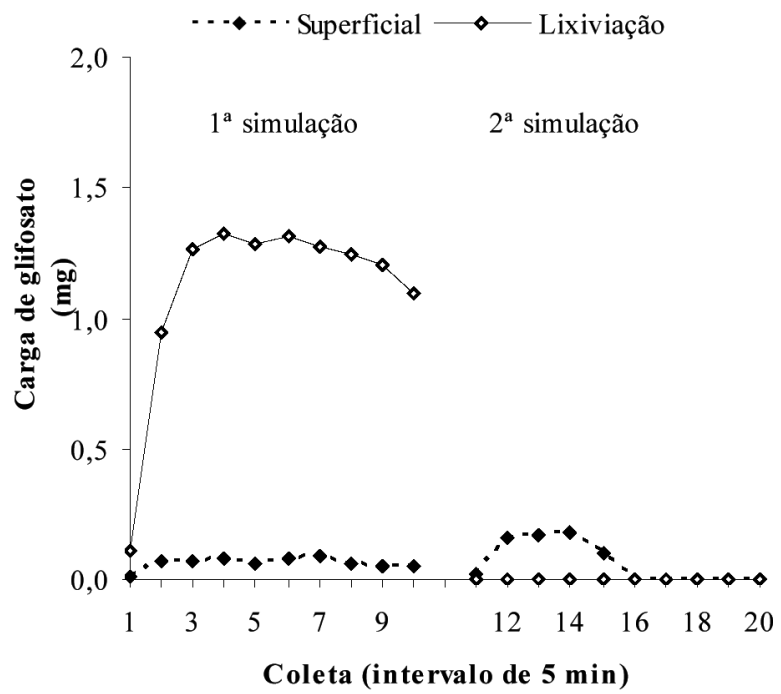

Figura 3. Cargas de glifosato em amostras de água no escoamento superficial e na lixiviação

transporte pelo escoamento superficial foi da ordem de $0,05 \mathrm{mg}$, enquanto que a totalidade da lixiviação ocorreu neste dia de simulação.

No lisímetro de $1 \mathrm{~m}^{2}$ de superfície foram aplicados $2 \mathrm{~kg} \mathrm{ha}^{-1}$ do produto comercial, perfazendo um total de $72 \mathrm{mg}$ de ingrediente 


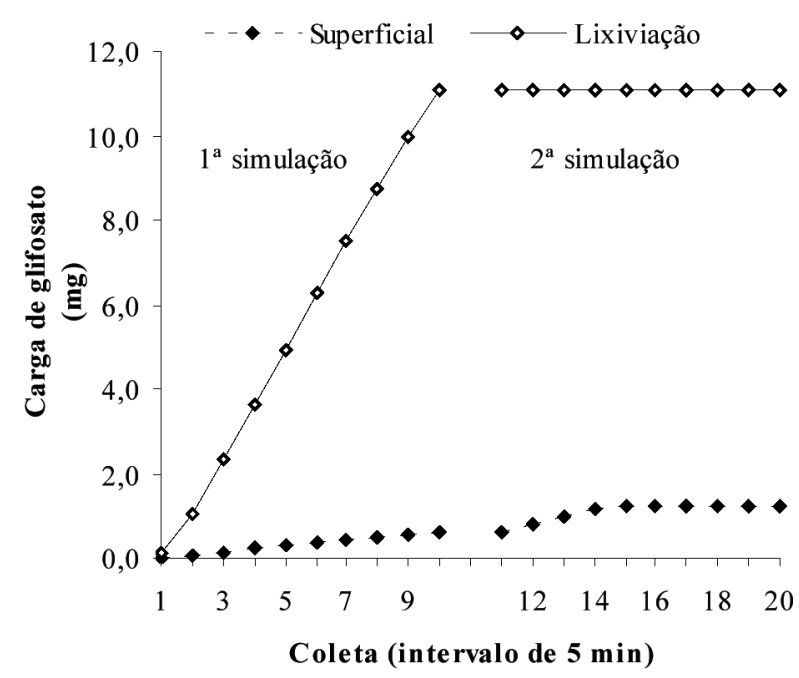

Figura 4. Cargas acumuladas de glifosato em amostras de água no escoamento superficial e na lixiviação

ativo. Comparando com as cargas acumuladas transportadas pelo escoamento superficial e pela lixiviação no lisímetro, tem-se que foram exportados para o ambiente exterior cerca de $17,1 \%$ do total de ingrediente ativo aplicado. $\mathrm{O}$ escoamento superficial transportou $1,7 \%$ e a lixiviação $15,4 \%$.

Em um monitoramento de uma área agrícola na Finlândia, durante 302 dias após a aplicação de glifosato, a quantidade transportada pelo escoamento superficial e pela lixiviação foi da ordem de $0,2 \%$ do total aplicado. ${ }^{36}$

Outros pesquisadores estudaram o transporte do glifosato em dois solos utilizados no cultivo de uva, durante um período de 1 ano, em que foram aplicados $673 \mathrm{~mm}$ de precipitação. A quantidade transportada foi de 0,06 e $0,15 \%$ do total de ingrediente ativo aplicado. ${ }^{37}$

Em um estudo envolvendo o transporte de glifosato em colunas com dois solos, um arenoso e outro silte-arenoso, foi feita uma simulação de precipitação. Diferentes tratamentos foram realizados e as quantidades de glifosato transportadas pela água variaram entre 0,04 e $19,6 \%$ do total aplicado. Nos solos arenosos o transporte foi inferior a $0,28 \% .{ }^{38}$ É importante ressaltar que um solo silte-arenoso estruturado, com elevada proporção de macroporos, pode favorecer a mobilidade de um pesticida com alto coeficiente de adsorção.

Assim, pode-se verificar, a partir deste trabalho, que as quantidades transportadas, em condições naturais, podem ser mais baixas. As precipitações simuladas apresentaram intensidades extremas. Isto significa que os totais exportados representaram também condições extremas, com valores maiores aos que poderiam ser obtidos em condições naturais.

Além disto, dois aspectos devem ser considerados na análise das quantidades obtidas na simulação. A quantificação foi realizada com base nas concentrações detectadas pelo processo analítico adotado. Concentrações inferiores ao limite de detecção podem ter sido exportadas e não foram consideradas no total calculado. A quantidade exportada pela lixiviação foi elevada e, em condições naturais, este escoamento poderia representar uma contribuição às camadas mais profundas do solo, sendo capaz de alcançar as águas subterrâneas.

\section{CONCLUSÕES}

A simulação de chuva no lisímetro de um solo agrícola, que recebeu a aplicação de glifosato, mostrou que as concentrações de glifosato nas águas escoadas superficialmente são superiores àquelas escoadas no perfil do solo. No escoamento superficial, o glifosato foi detectado no primeiro dia e nas primeiras amostragens do segundo dia de simulação de chuva. Na lixiviação, o herbicida foi detectado apenas na simulação realizada no primeiro dia. No entanto, quando o transporte foi avaliado em termos das cargas de glifosato, pode-se verificar que na lixiviação a quantidade transportada foi de cerca de 9 vezes superior à do escoamento superficial. Essa carga resultou da vazão escoada, que foi muito maior na lixiviação. Nessas condições, o glifosato poderia representar um risco de degradação de águas subterrâneas, principalmente, quando o nível do lençol freático estiver próximo da superfície e chuvas intensas ocorrerem imediatamente após a aplicação da substância.

\section{AGRADECIMENTOS}

À Profa. Dra. N. M. dos R. Castro, do Instituto de Pesquisas Hidráulicas da Universidade Federal do Rio Grande do Sul, pelo auxílio na estrutura de simulação de chuva e à FINEP pelo financiamento do projeto de pesquisa.

\section{REFERÊNCIAS}

1. Cserháti, T.; Forgács, E.; Deyl, Z.; Miksik, I.; Eckhardt, A.; Biomed. Chromatogr. 2004, 18, 350.

2. Javaroni, R. C. A.; Landgraf, M. D.; Rezende, M. O. O.; Quim. Nova 1999, 22, 58 .

3. http://www.agrural.com.br/index.php?option=com_content\&task=view \&id=29531\&Itemid=233, acessada em Setembro 2009.

4. Toni, L. R. M.; Santana, H.; Zaia, D. A. M.; Quim. Nova 2006, 29, 829.

5. Amarante Jr, O. P.; Santos, T. C. R; Brito, N. M.; Ribeiro, M. L.; Quim. Nova 2002, 25, 420.

6. http://www.inchem.org/documents/ehc/ehc/ehc159.htm, acessada em Setembro 2009.

7. Martínez, A.; Reyes, I.; Reyes, N.; Biomédica 2007, 27, 594.

8. Benachour, N.; Séralini, G.; Chem. Res. Toxicol. 2009, 22, 97.

9. http://www.esalq.usp.br/departamentos/lpv/download/2\%20-\%20 comportamento $\% 20 \mathrm{dos} \% 20$ herbicidas $\% 20$ na $\% 20$ ambiente.pdf, acessada em Setembro 2009.

10. Prata, F.; Lavorenti, A.; Rev. Biociênc. 2000, 6, 17.

11. Amarante Jr, O. P.; Santos, T. C. R.; Brito, N. M.; Ribeiro, M. R.; Quim. Nova 2002, 25, 589.

12. FOOTPRINT - Pesticide Properties Database, disponível em http:// sitem.herts.ac.uk/aeru/ footprint/en/index.htm, acessada em Junho 2010.

13. Silva, M. D.; Peralba, M. C. R.; Mattos, M. L. T.; Pesticidas: R. Ecotoxicol. e Meio Ambiente 2003, 13, 19.

14. Souza, T. A.; Matta, M. H. R.; Montagner, E.; Abreu, A. B. G.; Quim. Nova 2006, 29, 1372.

15. Candela, L.; Álvarez-Benedí, J.; Melo, M. T. C.; Rao, P. S. C.; Geoderma 2007, 140, 8.

16. Chen, Z.; He, W.; Beer, M.; Megharaj, M., Naidu, R.; Talanta 2009, 78, 852.

17. Zelenkova, N. F.; Vinokurova, N. G.; J. Anal. Chem. 2008, 63, 871.

18. Dickson, S. J.; Meinhold, R. H.; Beer, I. D.; Koelmeyer, T. D.; J. Anal. Toxicol. 1988, 12, 284.

19. Jan, M. R.; Shah, J.; Muhammad, M.; Ara, B.; J. Hazard. Mater. 2009, 169,742 .

20. Friestad, H. O.; Broenstad, J. O.; J. AOAC Int. 1985, 68, 76.

21. Alferness, P. L.; Iwata, Y.; J. Agric. Food. Chem. 1994, 42, 2751.

22. EPAGRI - Empresa de Pesquisa Agropecuária e de Extensão Rural de Santa Catarina; Zoneamento Agroecológico e Socioeconômico do Estado de Santa Catarina, 1999.

23. EMBRAPA - Empresa Brasileira de Pesquisa Agropecuária; Solos do Estado de Santa Catarina, 2004, Boletim de pesquisa e desenvolvimento, 46 . 
24. Kaufmann, V.; Dissertação de Mestrado, Universidade Regional de Blumenau, Brasil, 2009.

25. Oliveira, N. T.; Castro, N. M. R.; Goldenfum, J. A.; RBRH 2010, 15, 93.

26. Pinheiro, A.; Kaufmann, V.; Zucco, E.; Depiné, H.; Castro, N. M. R.; Soares, P. A.; Perazzoli, M.; R. Estudos Ambientais 2010, 12, 73 .

27. Ghanem, A.; Bados, P.; Kerhoas, L.; Dubroca, J.; Einhorn, J.; Anal. Chem. 2007, 79, 3794.

28. Zhu, Y.; Zhang, F.; Tong, C.; Liu, W.; J. Chromatogr., A 1999, 850, 297.

29. Veiga, F.; Zapata, J. M.; Fernandez Marcos, M. L.; Alvarez, E.; The Science of the Total Environment 2001, 271, 135.

30. Peruzzo, P. J.; Porta, A. A.; Ronco, A. E.; Environ. Pollut. 2008, 156, 61.

31. Battaglin, W. A.; Kolpin, D. W.; Scribner, E. A.; Kuivilla, K. M.; Sandstrom, M. W.; Journal of the American Water Resources Association 2002, 41, 323 .

32. Armas, E. D.; Monteiro, R. T. R.; Antunes, P. M.; Santos, M. A. P. F.; Camargo, P. B.; Abakerli, R. B.; Quim. Nova 2007, 30, 1119.
33. Brasil, Conselho Nacional do Meio Ambiente; Resolução $n .^{\circ}$ 357, de 17/3/2005. Dispõe sobre a classificação dos corpos de água e diretrizes ambientais para o seu enquadramento, bem como estabelece condições e padrões de lançamento de efluentes, e dá outras providências.

34. Brasil, Ministério da Saúde; Portaria $n .^{\circ} 518$, de 25/3/2004. Estabelece os procedimentos e responsabilidades relativos ao controle e vigilância da qualidade da água para consumo humano e seu padrão de potabilidade, e dá outras providências.

35. Back, A. J.; Chuvas intensas e chuvas de projeto de drenagem superficial no estado de Santa Catarina, Epagri Boletim Técnico, 123, 2002.

36. Siimes, K.; Rämö, S.; Welling, L.; Nikunen, U.; Laitinen, P.; Agricultural Water Management 2006, 84, 53.

37. Landry, D.; Dousset, S.; Fournier, J-C. ; Andreux, F.; Environ. Pollut. 2005, 138, 191.

38. De Jonge, H.; De Jonge, L. W.; Jacobsen, O. H.; Pest Manage. Sci. 2000 , $56,909$. 